\title{
Managing Optimism Biases in the Delivery of Large-Infrastructure Projects: A Corporate Performance Benchmarking Approach
}

\author{
Matti Siemiatycki ${ }^{1}$ \\ Department of Geography and Program in Planning, University of Toronto
}

\begin{abstract}
Optimism bias has been a considerable challenge in the planning and delivery of public services, particularly infrastructure mega projects. This has resulted in consistently underestimated costs and overestimated benefits, as well as delivery delays. This paper explores whether innovative mechanisms of collecting and publicly disseminating information about the performance of government contractors on past projects can contribute to improving the success rate of future initiatives. Drawing on international examples from North America, Europe and Asia, it is found that the production and dissemination of greater information through benchmarking does not on its own lead to reductions in the prevalence of optimism biases. However, there is evidence that when combined with incentives built formally into government procurement processes that reward strong past performance, benchmarking can support improvements in the quality of project outputs.
\end{abstract}

\section{Introduction}

Optimism bias is the inclination for people to be overly positive when making predictions about the outcomes of future planned actions. Optimism bias has been a considerable challenge in the planning and delivery of public services, particularly infrastructure mega projects. Evidence from the past century suggests that costs and delivery times are consistently underestimated and benefits overestimated in the development of new transport, water, waste, energy, schools and hospital facilities. For example, a study by Bent Flyvbjerg and his colleagues (2003) of more than 200 transport mega projects in 20 countries on five continents found that development costs were on average $28 \%$ higher than forecasted. Conversely, facility usage forecasts had inaccuracies that averaged between $9 \%$ and $39 \%$ depending on the type of infrastructure.

While forecasting an uncertain future is inherently difficult and face technical challenges, these technical challenges alone do not explain forecast inaccuracies (van Wee, 2007; Al-Momani, 1996). Rather, studies have shown that political and institutional factors embedded in the way that large

1100 St. George St., Toronto, Ontario, M5S 3G3, T: (416) 946-5145 E: $\underline{\text { matti.siemiatycki@utoronto.ca }}$ 
infrastructure projects are delivered create situations where few involved parties have a direct interest in avoiding unrealistic evaluations during the decision making process (Altshuler and Luberoff, 2003; Flyvbjerg et al., 2003; Ahadzi and Bowles, 2004; Hall, 1982). Against this backdrop, Flyvbjerg $(2007 ; 2004)$ suggests that a key step to minimizing optimism biases in project delivery is to create institutional cultures that normalize and reward accurate forecasting and construction management, while de-legitimizing the practice of being overly optimistic.

In recent years, a variety of strategies have been adopted to create institutional cultures that redress the tendency towards systematically overoptimistic forecasting. In the United Kingdom, for instance, the Department for Transport recommends that forecasters add 'optimism uplifts' to their projected capital costs for new schemes to account for the history of underestimated costs. Comparing forecasts against a comparable reference class of completed projects has also gained popularity as a method to gauge the accuracy of projections. More prominently worldwide, new models of contracting and project delivery - such as private-public partnerships which bundle infrastructure design, construction, finance and operation into a single long term contract with a private concessionaire have been encouraged as a way of transferring risk from the public to the private sector, increasing accountability, and improving project performance. To date, amidst considerable debate, there is mixed evidence about the degree to which the new partnership models of project delivery have improved the accuracy of pre-development forecasts (Pollock et al., 2007).

Another approach to improve the accuracy of forecasting that has been experimented with, which can be used alongside both conventional and alternative models of project delivery, is the introduction of benchmarking and contractor prequalification systems. Although performance benchmarking has been extensively used in sectors such as education, health care, financial services and consumer products, there has been a slower uptake of systematic measures to compare the quality of outputs by firms involved in planning and delivering public infrastructure.

This paper examines whether the introduction of corporate performance benchmarking on past projects, which are linked to the process of selecting contractors for future projects, provide a viable mechanism to reduce the level of optimism biases that have challenged the planning and delivery of large-scale infrastructure. This research fills a gap in the literature on managing cost overruns in the delivery of large infrastructure projects, where there has been only limited study of corporate performance benchmarking from either a theoretical or applied perspective.

The remainder of this paper proceeds in six sections. Section two identifies the diverse causes of inaccurate forecasts during the planning and delivery of large infrastructure projects. Section three examines the theoretical benefits and challenges associated with introducing performance benchmarking in the infrastructure sector. Sections four and five move from theory to practice, and explore the contemporary application of performance benchmarking in the infrastructure sector. In the penultimate section six, proposals are made to improve the utility of benchmarking for infrastructure projects. Finally, in section seven, conclusions are drawn about the potential for benchmarking approaches to enhance the infrastructure project delivery process.

\section{Causes of Poor Performance}

Around the world, the development of large infrastructure projects follows a relatively similar delivery process. During the project appraisal and delivery process, forecasts focus on two key issues: the construction cost, construction completion timeline and operations of the project (facility supply); and how the facility will be used once opened (facility demand), which impacts on the environmental, social and economic benefits of the project. 
Inaccurate forecasts of facility supply and demand are caused by a variety of factors, some of which are genuine errors, and others which result from the strategic actions of those involved in the forecasting and promotion of a specific project alternative. Forecasting an uncertain future is inherently difficult, and there are serious technical challenges related to poor data quality, incomplete methods and models, limited time allocated to analysis, and changes in the specifications and scope of the project under evaluation (Flyvbjerg et al., 2002).

Beyond technical challenges, however, academic research shows that forecasts which are systematically over-optimistic are caused by the interrelation of socio- psychological and political economic forces. As a type of interaction made between people, forecasts are affected by social norms, conventions of behaviour and individual and organizational psychology (Sedikides et al., 2002). When making predictions about the future, individuals demonstrate overconfidence about their own abilities and control of a situation. And within organizations that have only limited time and resources to pursue new initiatives, large incentives are in place for individuals to accentuate the positives when forecasting the benefits of their own plans (Lovallo and Kahneman, 2003). Moreover, theories of delayed discounting show that behaviour is most influenced by immediate rather than long-term consequences, particularly when mechanisms are not in place to create accountability for specific short term decisions (Pezzo et al., 2006).

This general lack of long-term accountability mechanisms for some parties involved in the championing, planning and delivery of infrastructure mega projects has created the space for the propagation of systematically optimistic forecasts. During the early planning stages when project alternatives are developed and appraised, there are often strong incentives for project supporters to overestimate project benefits and underestimate project costs, so that the scheme has a better chance of obtaining approval. And contractors may intentionally or implicitly produce bids that are unrealistically low in order to fit within publicly acceptable funding packages or to beat their competition, with the knowledge that governments have typically covered subsequent cost escalations when they occur (Flyvbjerg and COWI, 2004). Indeed, as Flyvbjerg and COWI (2004: 50) argue, systematic misrepresentation of costs and benefits has become so deeply embedded at all stages of the project delivery processes that it has become part of the routine informal 'rules of the game.'

Forecasts have come to be seen as the product of systemic institutional pressures that situate bureaucrats and consultants as political agents in the shaping of investment outcomes (Hall 1982). To this end, technical information such as forecasts are increasingly identified as persuasive rhetorical devices used by planners and project promoters to shape political and public support for specific initiatives (Throgmorton 1991). At the same time, articles such as 'When planners lie with numbers' (Wachs 1988) and 'The lying game' (Flyvbjerg 2003) illustrate that there is often a systemic pattern of misinformation on the part of some project proponents, which can be used to support the development of specific schemes.

\section{The Theory of Benchmarking}

Faced with technical challenges predicting an uncertain future as well as persistent optimism biases related to the cost, punctuality and performance of large-scale infrastructure, government and non-government organizations in a number of countries around the world have sought to improve the quality and cost effectiveness of service provision by designing benchmarking systems. Such systems compare the performance of companies that are involved in the provision of various aspects of public infrastructure, and integrate this information into the selection of firms for future contracts. 
The integration of expanded corporate performance benchmarking into public sector procurement systems can contribute to reshaping the social relationships and political-economic institutional forces that have supported the proliferation of optimism biases in project delivery. This occurs in three primary ways.

First, public sector decision makers responsible for approving contracts have more information about the past performance of firms bidding for contracts, providing an empirical basis upon which to select firms that have a strong record of delivering high quality outputs, punctually and on budget (Geraedts and Wamelink, 2007). Over the long term, the widespread availability of benchmarked data comparing performance of individual firms has been found to make corporate reputation and future contract awards more closely based on actual performance, rather than perceptions, marketing and public relations targeted at key decision makers (Maxey et al., 2003). This removes a key asymmetry of information challenging public sector decision makers, who may not have complete information about the actual performance of firms on pervious contracts that were carried out for other government bodies or in other jurisdictions.

Second, as was found in a 2005 United States Federal Highway Administration's study of international construction management practices, as greater amounts of data on corporate performance are compiled, widely published, and integrated into the process to select future contractors, there is an increased incentive for firms to strive to deliver high quality outputs. With more transparently available information about corporate performance, a firm's reputation becomes linked with delivering accurate forecasts and high quality work, instead of delivering results that may satisfy clients in the short term. To this end, the connection of high benchmarking scores based on past performance and the allocation of future contracts provides an incentive to link the short and long term interests of firms participating in public sector infrastructure development, by increasing the long term consequences of making inaccurate forecasts or delivering a low quality product. As a result, firms not only have an incentive to clamp down on the strategic factors that cause overly optimistic forecasts; they also have a strong incentive to research, develop and utilize the most innovative forecasting and delivery methods in order to achieve high quality results.

Third, beyond fulfilling strictly managerial or utilitarian objectives, the public release of extensive performance data has been encouraged by a new school of public sector management, as a mechanism to enhance the democratization and transparency of government decision making. The public release of performance data fulfills a demand by citizens for more information about the efficiency and effectiveness of public programs and spending. And equipped with greater information, it is argued that citizens are able to more meaningfully scrutinize and engage in the processes of planning large infrastructure projects in their communities (Pollitt 2006; Holden 2001).

While intuitively simple, in practice, the effectiveness of benchmarking to improve the performance of infrastructure delivery faces four main challenges. First, the implementation of benchmarking systems can result in a series of unintended consequences, or perverse reactions, that undermine the effectiveness of the system. In order to obtain high benchmark scores and therefore gain advantage in obtaining future contracts, it is possible that firms may rush their jobs, thereby creating unsafe work environments, reduce product quality in order to meet their cost obligations, or undertake aggressive measures to reduce labour costs. And there is a risk that prequalification systems that preference high performing firms may limit the intensity of competition for contracts, which can lead to long-run increases in project costs.

Second, the reduction of complex planning and project delivery processes down to a set of simple key performance indicators may undervalue the significance of the local context in which projects are planned, and lead to inaccurate conclusions about the performance of firms working in local 
communities. Third, compiling comprehensive benchmarking data can be costly and time consuming, and require ongoing project monitoring. Finally, beyond their uses by expert communities, Pollitt (2006) found little evidence that performance data is being read or used by politicians or citizens, thus limiting the effectiveness in democratizing planning decisions.

The above review shows that that there are both potential opportunities and challenges associated with the introduction of corporate performance benchmarking in the infrastructure sector. A significant aim for the remainder of this paper is to demonstrate that while these practical challenges are not necessarily insurmountable, they do require specific strategies if they are to be overcome.

\section{International Application of Benchmarking}

Based on the theoretical benefits, benchmarks and league tables have become increasingly popular in the infrastructure sector. According to a Dutch study, as of 2004 there were approximately 40 different benchmarking systems being used in the construction and infrastructure development sector worldwide (Bakens et al., 2004).

In Europe and North America, public sector led prequalification systems are typically based on the financial strength of the company, the structures it has in place to manage and deliver projects and its capabilities to carry out projects based on existing workload, rather than detailed evaluations of past performance of the projects that the company has delivered (FHWA, 2005).

Among the two international leaders in the transportation sector are the Ontario Ministry of Transportation in Canada and the Highway Agency in the United Kingdom, which each compile data on company finance and management procedures that are used to inform the selection of contractors for future projects (FHWA, 2005). In Ontario, the Ministry of Transportation assigns a consultant performance ranking for each firm completing public contracts, which assess the timeliness and quality of outputs against the original contract specifications. Each company can view their own ranking; however this data is not made widely available to the public.

When evaluating companies for future Ontario government contracts, the bidder's performance ranking based on past performance accounts for $50 \%$ of the grade, with price and technical specifications of the bid comprising the other $50 \%$ of the total score. With strict rules in place to ensure that the performance of all partners of joint ventures or consortiums is included in the same application, there is an incentive for companies to partner with firms that have strong past performance. There is also an incentive for firms to monitor the performance of their partners on an ongoing basis (MTO Qualification Committee, 2006).

In the United Kingdom, participation in the Highway Agency's prequalification system is voluntary, and requires a self assessment of a company's capabilities and management in areas such business development, risk management and health and safety, which is then verified by external auditors. The final rankings of the companies are released publicly on the agency's website, and have attracted coverage in the trade press. For companies with high rankings, the results have been promoted on their own websites and in their marketing and investor relations material, as a marker of the quality of their output and reputation. This suggests that firms are using the results of the objective led evaluation process as part of the package of information to shape their reputation and compete with other firms in the industry.

A key challenge to date in the Highway Agency's benchmarking system has been cost. The trade publication Contract Journal has reported that producing a benchmark entry can cost a firm up to half a million pounds in time and resources, which some contractors claim is too expensive (Pearman 
2007). As well, the results of the Highway Agency's performance rankings have not attracted coverage by the mainstream media, raising questions about how wide the dissemination of the ranking information has been beyond a series of expert communities.

In housing development and construction, Asian jurisdictions such as Hong Kong and Singapore have gone further than their North American and European counterparts in measuring both the input and output performance of contractors working on public sector projects, and integrating these results into the decision making process for future public procurements. In Hong Kong since 1991, the Hong Kong Housing Authority has developed the Performance Assessment Scoring System (PASS) which is intended to fairly and objectively measure contractor performance. Through unannounced site inspections and record checks, assessment teams are able to evaluate a company's delivery and maintenance of projects against defined architectural, structural, management and environmental standards. The evaluations are then used to select better performing contractors to take part in future tenders (Kam and Tang, 1997). A review of Hong Kong's experience by Tam et al. (2000) suggests that there are significant variations in performance between firms, with large firms performing better than smaller ones, and thereby solidifying their market share over time.

The analysis by Tam et al. (2000) found that amidst strong demand for contractors on private developments, the general level of quality has not been significantly improved in the construction of Hong Kong public housing, because the tendering process does not provide great enough financial incentive for companies to deliver a high quality product or improve upon their past performance. Bid selection criteria are based primarily on lowest cost, which has meant that producing a quality output has come at the expense of delivering projects punctually and on budget. Finally, because the preferential tendering system only considers PASS ratings of performance over the previous six months, Kam and Tang (1997) found that there were complaints of low quality flats being constructed by some firms with high PASS ratings, which had simply improved their performance before they planned to bid on new contracts.

Addressing some of the challenges identified in the Hong Kong PASS program, the construction quality assessment system set up for public sector residential building in Singapore (CONQUAS) since 1989 provides a more direct and ongoing financial incentive to companies that produce high quality outputs. The system is particular designed to measure the architectural and construction quality of a contractor's output and other service aspects. For every point over a score of 65 that a company receives on their quality assessment, they are awarded a tendering advantage of $0.2 \%$ up to a maximum of $5 \%$ or $\$ \$ 5$ million (which ever is less) on future contracts. This means that for instance if a company receives a score of 75 , they will be awarded a contract if their bid is within $2 \%$ of the price of their nearest competitor, although they will be paid at the original bid price (Tam et al., 2000). Despite being only a small premium, Kam and Tang (1997) found that the incentive program has been effective. As a result of the financial incentive built into the tendering process that rewards ongoing quality development, the average ranking and number of companies on the premium list has increased steadily, reflecting a rise in the overall quality of construction on public sector projects in Singapore. The CONQUAS results for individual firms and projects are published on a publicly accessible, searchable website maintained by the Building and Construction Authority.

Academic studies of the firms taking part in both the PASS and CONQUAS prequalification system have found similar results. While the majority of firms surveyed welcomed the introduction of a systematic mechanism to measure and compare performance, two fifths of respondents in Singapore and less than half in Hong Kong felt that the analysis was suitably impartial. In each case, there was concern that the metrics were not suitable to differentiate varying levels of quality, and that the assessors were not necessarily fully impartial (Kumaraswamy, 1996; Ofori, 1994) 
Overall, the international evidence shows that the implementation of benchmarking systems in the infrastructure sector to date have had both intended and unintended consequences. An important insight from the international experience is that the benchmarking of corporate performance on past projects alone is not enough to ensure improved quality on future projects. Rather, as in the system implemented in Singapore, formalized structures that integrate the benchmarking results into the final stages of future government procurement processes provide the strongest incentives to companies to deliver high quality projects on an ongoing basis.

The international experience to date also suggests that carrying out benchmarking involving extensive internal process reviews is expensive in terms of time and money for the firms involved. The introduction of prequalification systems can adversely impact on the competitiveness for contracts, when they reinforce the dominant position of large firms. Finally, in a number of cases, efforts have been made to widely publicize the audit results. Nevertheless, it remains unclear the extent to which this data has been used beyond managerial ends, to better engage citizens in community planning processes and decision making.

\section{Output Oriented Corporate Benchmarking: A Collaborative Approach}

Based on evaluations of the strengths and limitations of long-running benchmarking and prequalification systems used in North America, Europe and Asia, a number of innovative schemes have more recently been designed. In particular, these schemes have placed greater emphasis on developing comprehensive measures to benchmark performance outputs as well as corporate inputs. New partnership and private sector models for collecting and disseminating the benchmarked data have also been developed. Together, these new systems of corporate benchmarking have been designed in order to overcome challenges related to the accuracy of the benchmarks themselves, and participation cost.

A system implemented in the Danish construction industry in 2005 provides an example of the possibilities of an innovative benchmarking system that focuses on project outputs. Faced with a historical record of poor performance in the Danish construction sector, in 2001, members of the construction industry partnered with the Danish Government to set up the Benchmarking Centre for the Danish Construction Industry (BCE). The BCE was fully funded by the private sector as a commercial foundation, with a mandate to develop and disseminate information as part of a benchmarking system. Nearly half of its revenue is generated through the sale of project evaluations to industry sources such as contractors and sub-contractors who are required to have a sample of their projects benchmarked to take part in public sector tenders; the remainder of its funding comes from industry and private foundation contributions.

In 2003, the Danish government passed legislation making it mandatory that all firms bidding for state government contracts over the equivalent of $£ 500,000$, excluding infrastructure projects, must demonstrate that the quality of their past performance met a minimum set of standards. To meet this objective, the BCE developed a grade book system, where for a sample of government contracts that a company completes, their performance is objectively evaluated based on a series of fourteen key performance indicators. The key performance indicators cover aspects of project delivery such as occupational safety, punctuality, quality of the workmanship based on the number of defects, accuracy in meeting budgets, profitability, labour productivity and client satisfaction.

The accuracy of the data supplied by the companies is verified by the $\mathrm{BCE}$, and the grade book is then submitted to a government client along with the company's tender proposal for each new job. By measuring such a wide range of performance indicators, the Danish benchmarking system is 
designed to minimize the perverse incentive of reducing quality or safety to meet cost and punctuality targets.

According to a report by the $\mathrm{BCE}$, the collaborative approach was critical to obtaining support for the benchmarking initiative from the construction industry.

'Introduction of compulsory benchmarking constitutes an administrative burden on companies and is not necessarily a popular measure. The reason the initiative has succeeded is largely due to the fact that BEC was formed by the organizations in the construction sector, which have seats on the Directors Board and have been backing the system actively.' (Mortensen and Lind Kristensen 2006: 5)

Through close public and private sector collaborations in the design of the benchmarking system, the $\mathrm{BCE}$ reports that the typical time that it takes for a company to carry out their requirements for the benchmarking of a single project is 3.5 hours, and ongoing efforts are being taken to reduce this time further.

In Denmark, the implementation of a robust benchmarking framework makes it possible to compare companies based on their output performance. In addition to prequalifying bidders, the data has been used to carry out extensive studies of performance within the construction sector based on project type, contract structure, and by geography, and develop best practices. While the studies are released publicly, the results for individual firms and projects are kept confidential.

A key limitation of the Danish benchmarking system is that it was primarily designed to pre-qualify bidders for government contracts above a minimum standard, and to date there has not been universal action within government agencies to formally integrate the benchmarks into the final process of selecting the winning bidder. This means that there is not necessarily a strong ongoing incentive for firms to strive to improve their performance over time above a minimum standard needed to prequalify for government contracts. The result has been that with respect to cost overruns on certain types of projects such as cultural facilities, for instance, there has not been a significant reduction in the size of cost overruns on benchmarked projects between 2001 and 2006 (Byggeriets Evaluerings Center, 2007).

A second limitation is that resulting from a separation in the government departments responsible for construction and infrastructure when the plan was drafted, the benchmarking system does not apply to infrastructure initiatives. This is even though large infrastructure projects are typically the most costly and highest profile types of public projects, and have the greatest impacts when inaccuracies occur.

\section{The Future of benchmarking in the Infrastructure Sector}

To date, there have been two key limitations in the application of corporate performance benchmarking for managerial purposes in the infrastructure sector. First, such systems have been targeted predominantly at supply forecasts, and particularly construction cost and completion estimates which are the domain of building contractors and large engineering firms. In a smaller number of cases, benchmarking has focused on construction quality, and tracked the ongoing performance of a facility once opened.

However, for the largest scale infrastructure projects, construction and facility supply are only one stage of the procurement process at which errors and optimism biases have resulted in worse than expected outcomes. During the project evaluation and planning process, demand forecasts related to 
facility patronage levels, user and community benefits have been key areas where inaccuracies have propagated.

Second, benchmarking has not been systematically applied to the development of infrastructure mega projects. This omission is significant, as Canadian evidence from the energy sector shows that the frequency and scope of cost escalations and delivery delays increase as the size of the project grows (Fayek et al., 2006).

Due to structural changes in the way that large scale infrastructure is delivered, benchmarking may be an increasingly valuable tool to reduce the prevalence of optimism biases and improve output quality. In many countries, an increasing share of project scoping, planning, design, and testing functions for the delivery of public infrastructure are being outsourced to private companies, at the same time as the size of public bureaucracies are being reduced. In the transport sector, for instance, a comparative review of road procurement practices in North America and Europe found that between $70 \%$ and $100 \%$ of the project delivery functions - project design, testing, construction, construction contract administration and maintenance - had been outsourced (FHWA, 2005).

At the same time, amidst an increasingly global industry, there are a relatively small number of firms taking lead roles in the largest infrastructure projects. This point is illustrated by data available for projects delivered worldwide through private-public partnerships, the sector for which the best data is available. According to data published by Public Works Finance (2006), between 1985 and 2006, only 13 firms were the main concessionaire for more than five water or waste water projects with a value of more than $\$ 50$ million, that were delivered through private-public partnerships. Over the same period in the transportation sector, 35 firms were the main concessionaire delivering more than four projects with capital valued at over $\$ 50$ million through private-public partnership projects. In any given country, the actual number of active firms competing for large transportation, waste, water and sewage contracts may be far less.

In a context where a relatively small number of private sector firms are playing an increasing role in all facets of project definition and delivery, corporate performance benchmarking and prequalification systems may be effective at linking a firm's short term performance with its long term reputations. To this end, leagues could be constructed to compare the performance of firms that deliver infrastructure within similar reference classes (ie. roads, bridges, rail lines, subways, waste and water facilities, schools, hospitals), and provide similar types of services (ie. financial evaluations, patronage or volume forecasts, project management, construction, system operation and financing).

Based on the international experience, benchmarks should be developed to cover a range of output criteria related to infrastructure supply, including cost certainty, punctuality of delivery, defects and change orders, service quality, worker safety and client satisfaction. Benchmarking the producers of demand forecasts represents a unique challenge since the accuracy of such estimates is heavily influenced by external factors such as public policy decisions and economic conditions, which may change suddenly.

Despite the challenges, Flyvbjerg et al. (2003) and Pickrell (1992) show that in addition to technical difficulties, systematic optimism biases are a common source of error in demand forecasts. Within this context, the introduction of benchmarking introduces incentives for firms to use the most advanced forecasting techniques available, apply realistic assumptions about future events, and challenge the personal and organizational forces that contribute to unrealistically favourable demand estimates.

Once comprehensive benchmarking tables are produced to compare performance, formal mechanisms should be developed to integrate the results into future procurement processes, providing firms with an ongoing incentive to drive up the quality of their performance. Such 
mechanism can include integrating past performance rankings directly into the public sector process for selecting future contractors on government projects as is carried out in Singapore.

At the same time, as private financing of public infrastructure becomes more prevalent globally through the application of private-public partnerships, banks, pension funds and insurance companies are increasingly putting large sums of money at risk in the infrastructure sector. With returns often based on the degree to which construction costs are controlled and volume and revenue forecasts are achieved, rigorous benchmarking of past performance by forecasters, designers, engineers, general contractors, and facility operators can serve as an important addition to investors existing due diligence process.

\section{Conclusion}

In recent years, the provision of high quality public infrastructure has been recognized around the world as a critical precondition for economic competitiveness and growth, environmental amelioration, and social inclusion. However, at the same time as infrastructure has risen up the political agenda, growing academic, media and public attention has focused on the frequency with which such projects fail to meet expectations, either through large construction cost overruns, late delivery, or lower than expected usage.

In response to these challenges, governments and non-governmental organizations in a number of countries have developed strategies to minimize inaccurate forecasting, including the use of 'optimism uplifts', reference class forecasting, and new contract structures such as private-public partnerships.

Alongside other strategies, in an increasing number of countries, systems have been implemented to benchmark the performance of contractors working on public projects, and link past performance with the likelihood of obtaining future work. The international experience suggests that the introduction of performance benchmarking in the construction sector on its own has not significantly reduced the presence of optimism biases. Nor has corporate benchmarking contributed to significantly democratizing planning decision making through widespread public dissemination and debate. However, when combined with incentives built into government procurement process that reward strong past performance, there is evidence that benchmarking can drive up the quality of project outputs.

\section{References}

Al-Momani, A.H. (1996). Construction cost prediction for public school buildings in Jordan. Construction Management and Economics, Vol. 14, No. 4, pp. 311-317.

Altshuler, A. and Luberoff, D. (2003). Mega-Projects: The Changing Politics of Urban Public Investment. Washington, DC, Brookings Institution.

Ahadzi, M. and Bowles, G. (2004). Public-private partnerships and contract negotiations: an empirical study. Construction Management and Economics, Vol. 22, No. 9, pp. 967-978.

Bakens, W., Vries, O. and Courtney, R. (2005). International Review of Benchmarking in Construction. PSI Bouw. Retrieved March 10, 2008, from http://www.psibouw.nl/

Byggeriets Evaluerings Center (2007). Budgetafvigelser pa kulturbyggerier i Danmark. Copenhagen, Byggeriets Evaluerings Center. 
Siemiatycki

Managing Optimism Biases in the Delivery of Large-Infrastructure Projects:

A Corporate Performance Benchmarking Approach

Federal Highway Administration (FHWA) (2005). Construction Management Practices in Canada and Europe. Available online at: http://international.fhwa.dot.gov/construction_mgmt/index.cfm (last accessed January 2010)

Fayek, A.R., Revay, S.O., Rowan, D. and Mousseau, D. (2006). Assessing Performance Trends on Industrial Construction Mega Projects. Cost Engineering, Vol. 48, No. 10, pp. 16-21.

Flyvbjerg, B. (2007). Policy and Planning for Large-Infrastructure Projects: Problems, Causes, Cures. Environment and Planning B, Vol. 34, No. 4, pp. 578-597.

Flyvbjerg, B. and COWI (2004). Procedures for Dealing with Optimism Bias in Transport Planning: Guidance Document. London, The British Department for Transport.

Flyvbjerg, B. (2003, June). The Lying Game. Eurobusiness, pp. 60-62.

Flyvbjerg, B., Bruzelius, N. and Rothengatter, W. (2003). Mega Projects and Risk: An Anatomy of Ambition. London, Cambridge University Press.

Flyvbjerg, B., Holm, M. and Buhl, S. (2002). Underestimating Costs in Public Works Projects: Error or Lie? Journal of the American Planning Association, Vol. 68, No. 3, pp. 279-295.

Geraedts, R. and Wamelink, H. (2007). Distinction Through Performance; A Measurement Instrument For Assessing The Process Quality Of Contractors Based On Past Delivered Performance. Second International Conference World of Construction Project Management. Retrieved March 10, 2008, from http://www.wcpm2007.nl/

Hall, P. (1982). Great Planning Disasters. London, Penguin Books.

Highway Agency (2006). CAT3 Supplier Information. Retrieved May 29, 2007, from http://www.highways.gov.uk/business/documents/CAT3_PH1_Suppliers.pdf

Holden, Meg (2001). Uses and abuses of urban sustainability indicator studies. Canadian Journal of Urban Research, Vol. 10, No. 2, pp. 217-237.

Kam, C.W. and Tang, S.L. (1997). Development and implementation of quality assurance in public construction and works in Singapore and Hong Kong. International Journal of Quality $\mathcal{E}$ Reliability Management, Vol. 14, No. 9, pp. 909-928.

Kumaraswamy, M.M. (1996). Contractor Evaluation and Selection: a Hong Kong Perspective. Building and Environment, Vol. 31, No. 3, pp. 273-282.

Lovallo, D. and Kahneman, D. (2003). Delusions of Success: How optimism undermines executives' decisions. Harvard Business Review, Vol. 81, No. 7, pp. 56-63.

Maxey, E. Kashiwagi, D. and Savicky, J. (2003). Selecting Designers Using The Performance Information Procurment System (Pips). Proceedings of The RICS Foundation Construction and Building Research Conference, Woverhampton, September 1-2.

Mortensen, S and Lind Kristensen, E. (2006). Benchmarking Danish Construction. Benchmarking Centre for the Danish Construction Centre, Copenhagen.

MTO Qualification Committee (2006). Consultant Performance and Selection System Consultant Appraisal Reviews Consultant Infraction Reports Procedures Guide (Revised). Ontario, Ontario Ministry of Transportation

Ofori, G. (1994). Managing Construction Industry Development: Lessons from Singapore's Experience. Singapore, NUS Press.

Pearman, R. (2007). Balfour Beatty tops Highways Agency's CAT score league. Contract Journal. 14 March. Retrieved April 18, 2009, from www.contractjournal.com 
Pezzo, S.P., Pezzo, M.V. and Stone, E.R. (2006). The social implications of planning: How public predictions bias future plans. Journal of Experimental Social Psychology, Vol. 42, No. 2, pp. 221-227.

Pickrell, D.H. (1992). A desire named streetcar: fantasy and fact in rail transit planning. Journal of the American Planning Association, Vol. 58, No. 2, pp. 158-176.

Pollitt, C. (2006). Performance Information for Democracy: The Missing Link? Evaluation, Vol. 12, No. 1, pp. 38-55.

Pollock, A. Price, D. and Player, S. (2007). An Examination of the UK Treasury's Evidence Base for Cost and Time Overrun Data in UK Value-for-Money Policy and Appraisal . Public Money \& Management, Vol. 27, No. 2, pp. 127-134.

Public Works Finance. (2006). Survey of Private Public Partnerships. Public Works Finance, 209, pp. 1-8.

Sedikides, C., Herbst, K.C., Hardin, D.P., and Dardis, G.J. (2002). Accountability as a deterrent to self-enhancement: The search for mechanisms. Journal of Personality and Social Psyhology, Vol. 83, No. 3, pp. 592-605.

Tam, C.M., Deng, Z.M., Zeng, S.X. and Ho, C.S. (2000). Performance assessment scoring system of public housing construction for quality improvement in Hong Kong. International Journal of Quality \& Reliability Management, Vol. 17, No. 4/5, pp. 467-478.

Throgmorton, J. (1991). Planning as a Rhetorical Activity. Journal of the American Planning Association, Vol. 59, No. 3, pp. 334-346.

van Wee, B. (2007). Large Infrastructure Projects: A Review of the Quality of Demand Forecasts and Cost Estimations. Environment and Planning B, Vol. 34, No. 4, pp. 611-625.

Wachs, M. (1988). When planners lie with numbers: An exploration of data, analysis and planning ethics. Los Angeles, University of California. 